\title{
AC 2008-2438: ENGINEERING ECONOMY ASSESSMENT OF BAYLOR'S PILOT GLOBAL BUSINESS COMMUNICATION COURSE
}

\section{Benjamin Kelley, Baylor University}

Dr. Benjamin Kelley is the Dean of Baylor University's School of Engineering and Computer Science. His area of technical expertise is in orthopedic biomechanics and cardiovascular dynamics. He is committed to a number of academic projects including global education, student life, and faculty development.

\section{Robert Doty, Baylor University}

Dr. Bob Doty serves as Professor of Mechanical Engineering in the School of Engineering and Computer Science at Baylor University. His research interests include Computer-Aided Design and Data Acquisition Systems. Dr. Doty designed and taught the engineering economy portion of the GBC course.

\section{Bill booth, Baylor University}

Mr. Bill Booth is a Senior Lecturer of Computer Science in the School of Engineering and Computer Science at Baylor University. He is director of the freshman Computer Science sequence. Among his areas of expertise is assessment and statistical analyses, and he conducted the assessment comparisons of the GBC course.

\section{Cynthia Fry, Baylor University}

Prof. Fry is the Assistant Dean of Undergraduate Studies and Senior Lecturer of Computer Science in the School of Engineering and Computer Science at Baylor University. She is also the Faculty-in-Residence at the Engineering and Computer Science Living Learning Center, where she lives with her husband and two children. 


\title{
Engineering Economy Assessment of Baylor's Pilot Global Business Communication Course
}

\begin{abstract}
Since 2001, faculty members and students in Baylor University's School of Engineering and Computer Science (ECS) have developed and participated in focused summer-abroad programs. These programs have matured from stand-alone courses to integrated experiences including global and cultural aspects and also business, economic and communication content. The benefits to and satisfaction of the students is significant. Most recently, around ten engineering and computer science students, and ten Baylor business students, participated each year. The six credits substitute for two courses of existing degree requirements. The specific course substitutions for ECS students depend on the student's major.
\end{abstract}

The level of faculty/staff effort and student expense to coordinate the summer abroad experience is extensive. Students who participate bear much of the additional financial burden associated with the program. For these reasons, it is not practical for a high percentage of ECS students to participate. Yet because the benefits of participating are great, it is desirable make them available to more Baylor ECS students. Therefore, an on-campus companion course sequence with similar learning objectives was conceived that can reach a greater numbers of students. A pilot version of the course, Global Business Communication (GBC), was offered for the first time during fall 2006. The second course in the sequence, Technology Entrepreneurship, is a new course offered through Baylor's Business School, in which adequately prepared business students may also enroll.

Like the abroad course, the on-campus GBC course must substitute for existing courses in the ECS curriculum. Engineering Economic Analysis is one of the possible course substitutions. Baylor engineering seniors perform on the Fundamentals of Engineering exam at a near 100\% pass rate. Because of the prominence of engineering economy on this exam, the ECS faculty determined that the GBC course, in combination with the follow-on Technology

Entrepreneurship course, should yield student outcomes at a level similar to the existing engineering economy course. This is a particularly challenging charge since the courses also cover global, communication, and entrepreneurship topics.

The performance of students enrolled in the first pilot offering of the GBC course, and a traditional engineering economy course offered the same semester, were compared. The assessment consisted of a comparison of the students' academic preparation, and pre- and posttest covering engineering economy topics. There was no statistical difference between the two student populations. Students who enrolled in the traditional engineering economy course performed at a higher level than students in the GBC course, including when test questions were weighted for applicability toward FE exam-type problems.

The second pilot offering of the GBC course occurred during the fall 2007 term. Several changes were made to increase students' engineering economy capabilities. 


\section{Background}

Engineering, computer science, and other technically-focused academic programs are inserting more global- and business-related initiatives into their curriculums and range of activities. This is in responsive to constituent feedback, accreditation criteria, and the realization that such knowledge is needed for their graduates to distinguish themselves. The need for the globalization aspect has been fueled largely by improvements in transportation, communication, and manufacturing. ${ }^{1,2}$ These technological advances have influenced and altered how business and commerce are conducted domestically and globally, and the organizational structures international corporations employ. ${ }^{3}$ It is interesting that the very innovations developed within the technology sector have the competing effects of increasing the need to add technical focus and specificity, while simultaneously increasing humanistic- and business-related content. ${ }^{4}$

Increasingly, the technological knowledge associated with an engineering or computer science degree is not assurance for career success, as a combination of professional skills is needed. ${ }^{4}$ Successful careers require an understanding of how a business functions and familiarity with contemporary issues in a global and societal context. ${ }^{5}$ A variety of innovative and successful approaches have been used to expose students to global issues. Selected engineering standards are used to lead into global manufacturing. ${ }^{6}$ The Engineering Projects in Community Service (EPICS) has a international component. ${ }^{7}$ A multi institution, multi country initiative seeks to promote international cooperation and generate new partnerships. ${ }^{8}$ Although engineering students traditionally have elected not to study abroad, new international programs and recruiters' expectations are leading more students to select this option. ${ }^{9}$ Some engineering abroad programs intentionally involve a business component. ${ }^{10,11}$

Efforts to better instruct and expose engineering students to business and economic platforms include partnerships incorporating entrepreneurship exercises, ${ }^{12}$ teams jointly comprised of engineering and business students, ${ }^{13,14}$ and common academic facilities. ${ }^{15}$ Such joint programs not only enhance the engineer's capabilities in business, but also expose business students to problems in technology, which also enhances their career potential and boosts U.S. competitiveness and innovation. ${ }^{16}$

A course in engineering economic analysis has long been the mainstay business-related course in engineering curriculums. ${ }^{17}$ Recent innovative applications in engineering economy courses include group problem solving activities, ${ }^{18}$ using only spreadsheets to solve assignments, ${ }^{19}$ assessing accreditation "soft skills" outcomes, ${ }^{20}$ and introducing contemporary global issues. ${ }^{21}$

\section{Introduction}

During most of the last decade Baylor's ECS programs have responded to the desire for students to be globally savvy by developing abroad experiences with an ECS focus. ${ }^{11,22}$ This experience matured into one that includes a partnership with the business school. Because of the high cost of this program, both in terms faculty and staff resources and student-program charges, it is not feasible to offer it for a majority of the students. This fact though, does not negate the desire that all ECS graduates be equipped with discipline-appropriate global knowledge. 
A faculty committee was charged with recommending curricular elements for an on-campus experience to equip ECS students with global and business knowledge while not diminishing other important academic topics. A limiting factor imposed on the committee included adding no additional credits to the curriculum. This caused the committee members to focus on adjusting or modifying courses common among the different ECS majors and that contained or taught complimentary topics. Because courses in Engineering Economic Analysis, Professional and Technical Writing, and Technical Speaking satisfied these criteria, they were selected for consideration. At least two of these courses are required in each of the ECS curriculums. It is believed that by integrating the topics covered in these courses they can be taught in a synergistic manner, while also adding global and other business topics. Simultaneous with this effort, a new emphasis in and partnership with the business school caused entrepreneurship and other business topics to be added to the mixture. ${ }^{23}$ The resulting recommendation is a two course sequence at the sophomore-junior level. The first course, Global Business Commutation (GBC), is targeted only at ECS students. The second course, Technical Entrepreneurship (TE), continues the threads begun in the GBC course in a project format, and is aimed at ECS and business students. On an interim basis, each ECS department approved that these two courses are permitted to substitute for two existing curriculum requirements. This is a similar arrangement as for the actual study-abroad ECS courses. The permitted substitutions vary by department and range from courses in engineering economy, technical writing, history/social science elective, technical elective, and even foreign language.

The existing and required Engineering Economic Analysis course is offered by a faculty member in the business school. It covers traditional engineering economy topics, including those that are perceived by some to be beyond what is tested on the Fundamental of Engineering exam.

Because this course is somewhat isolated in the business school, it is generally not thought of as one of the fundamental or integral engineering courses. Yet, because Baylor engineering seniors pass the FE exam at the highest rate in Texas, there is considerable pride and protection of the engineering economy topics in the curriculum. Therefore, the committee determined that the combination of the GBC and TE courses must yield learning outcomes sufficient for students to perform at a high level on the FE exam.

\section{The GBC Course}

During the fall 2006 semester, a pilot version of the GBC course was offered. It was team taught by three faculty members. The content responsibility was roughly divided into the areas of oral technical speaking, written technical writing, and engineering economy. A communication specialist from the business school taught the speaking portion and an ECS staff member taught the writing content. A senior engineering professor taught the engineering economy content. ${ }^{24}$

A small sample of sixteen students enrolled in the first pilot GBC offering; twelve electrical/computer engineering majors and four mechanical engineering majors. All of the students used the GBC course to substitute for their Engineering Economic Analysis course requirement. $^{25}$

The instructional strategy of the GBC course involved a series of two-week instructional cycles. Each of these cycles began with an introduction of a relevant research topic designed to provide 
the "global business flavor." Lectures in technical speaking, technical writing, and engineering economy followed. The cycle culminated in an evaluation where written assignments were submitted by half of the students, a video-tapped oral presentations were made by the other half, and a brief in-class quiz taken by all. A new research topic was then introduced and the twoweek cycle repeated, with the role of the students reversing with regards to written and oral submittals. This format resulted in six instructional cycles. The basic research business topics upon which the economic, writing, and communications topics centered during these cycles were: ${ }^{25}$

1. Foreign Currency Exchanges

2. International Stock Exchanges

3. Basic Financial Statements
4. Business Plan Components

5. Business Plan Overview

6. Business Plan Submittals

The specific engineering economy topics covered during each of the cycles were:
1. Spreadsheet Analysis/Discount
4. Bonds and Inflation Factors
5. Comparison of Alternatives
2. Cash Flow and Equivalence
3. Depreciation and Book Value
6. Fundamentals Review/Diagnostic Exam

The objective of the engineering economy portion of the GBC course was to provide the students with a sound understanding of the basic principals of engineering economics, with practice in applying these principals in a business context, and the knowledge and skills required for success on the engineering economics section of the FE exam. That was attempted through a series of lectures and spreadsheet projects on engineering economics integrated throughout the semester. Snapshots of lecture presentations on two of the five topical areas, depreciation and break-even analysis, are shown in Figures 1 and 2 below. $^{25}$

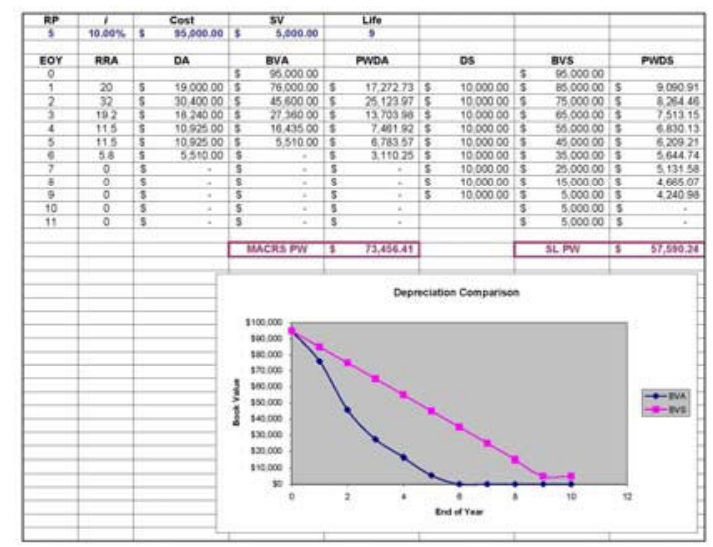

Figure 1: Depreciation spreadsheet solution.

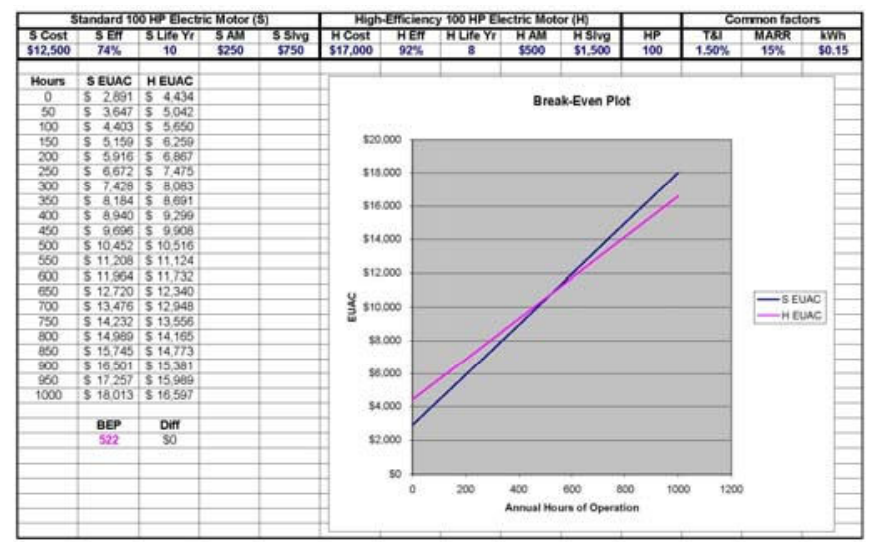

Figure 2: Break-even spreadsheet solution.

The depreciation scenario provided by the spreadsheet solution in Figure 1 above is: $:^{25}$ Develop an Excel spreadsheet that graphically compares depreciation of an asset by the straight-line method and the MACRS. The asset has a purchase price of $\$ 95,000$, and a salvage value of $\$ 5,000$, a service life of 9 years, and a recovery period of 5 years. Compute the present worth of the depreciations over the service life of the asset for each method, assuming an effective annual interest rate of $10 \%$. The 
learning outcome should be clear; the MACRS depreciation method is very attractive to profitable companies when compared to straight-line depreciation.

The break-even scenario provided by the spreadsheet solution in Figure 2 above is: ${ }^{25}$

Develop an Excel spreadsheet that performs a break-even analysis for two alternative $100 \mathrm{hp}$ electric motors using the EUAC method (revenues are assumed to be equal). A standard electric motor costs $\$ 12,500$ and has an efficiency of $74 \%$, a life of 10 years, maintenance expenses of $\$ 250$ per year, and a $\$ 750$ salvage value. A highefficiency motor costs $\$ 17,000$ and has an efficiency of $92 \%$, a life of 8 years, maintenance expenses of $\$ 500$ per year, and a $\$ 1,500$ salvage value. Annual taxes and insurance expenses for either motor will be $1 \frac{1}{2} \%$ of the capital cost and the MARR is $15 \%$ per year. Unit energy cost shall be a variable.

\section{Engineering Economy Evaluations and Comparisons}

The same semester as the GBC course was offered, a separate cohort of students were also enrolled in the traditional Engineering Economic Analysis course. The students in that course and the GBC course completed the same pre-course and post-course engineering economy exam. This exam was constructed by the engineering economy professor from the business school. ${ }^{26}$ So as to avoid "teaching to the exam," (vs. teaching to the FE exam) the engineering professor instructing the engineering economy component of the GBC course did not see this exam in advance of (or during) the course. The exam consisted of twenty multiple choice problems. The general topical area of each problem is shown in TABLE I. ${ }^{26}$

\begin{tabular}{||l|l|c|l||}
\hline \multicolumn{3}{|c|}{ TABLE I: Topical Area of Pre/Post Exam ${ }^{26}$} \\
\hline 1 & Time value of money & 10 & $\begin{array}{l}\text { Production and cost; profit calculation; } \\
\text { break-even analysis }\end{array}$ \\
\hline 2 & Time value of money & 11 & $\begin{array}{l}\text { Production and cost: profit calculation; } \\
\text { break-even analysis }\end{array}$ \\
\hline 3 & $\begin{array}{l}\text { Time value of money and the timing of } \\
\text { cash flows }\end{array}$ & 12 & Marginal analysis \\
\hline 4 & Time value of money & 13 & Bond valuation \\
\hline 5 & $\begin{array}{l}\text { Time value of money and the effect of } \\
\text { compounding }\end{array}$ & 14 & Capitalized equivalent \\
\hline 6 & $\begin{array}{l}\text { Time value of money and the effect of } \\
\text { compounding }\end{array}$ & 15 & Internal rate of return \\
\hline 7 & Inflation and nominal values & 16 & $\begin{array}{l}\text { Government deficit financing and interest } \\
\text { rates }\end{array}$ \\
\hline 8 & Inflation and real values & 17 & Financial statements \\
\hline 9 & Inflation & 18 & Depreciation and taxation \\
\hline 10 & Replacement Analysis & 19 & Benefit-cost analysis \\
\hline \hline
\end{tabular}

Examples of two of the problems on the exam that were considered of high relevance to the FE exam are shown in the two panels below. ${ }^{26}$ 
3. Two investments are being considered. Each investment requires an initial cash outlay of $\$ 10,000$. The expected year-end cash inflows for each investment are shown below:

\begin{tabular}{|c|c|c|}
\hline \multirow{2}{*}{} & \multicolumn{2}{|c|}{ Cash inflows } \\
\cline { 2 - 3 } & Investment X & Investment Y \\
\hline Year 1 & $\$ 2,000$ & $\$ 6,000$ \\
\hline Year 2 & $\$ 3,000$ & $\$ 5,000$ \\
\hline Year 3 & $\$ 4,000$ & $\$ 4,000$ \\
\hline Year 4 & $\$ 5,000$ & $\$ 3,000$ \\
\hline Year 5 & $\$ 6,000$ & $\$ 2,000$ \\
\hline
\end{tabular}

If the prevailing market interest rate over the coming 5 years is expected to be $3 \%$ per year:

a. Investment $\mathrm{X}$ will be preferred to Investment $\mathrm{Y}$.

b. Investment $\mathrm{Y}$ will be preferred to Investment $\mathrm{X}$.

c. Since the two investments generate the same total cash flows over their lifetimes, and the same market interest rate applies to each investment, an investor would have no reason to prefer one to another.

5. You are considering opening a new savings account at your local bank; you plan to deposit $\$ 100$ for one year. You are given three choices: an account paying 3\% simple interest per year, an account paying 3\% interest compounded annually, or an account paying 3\% per year compounded quarterly. If your goal is to earn the highest possible amount of interest on your account, you will choose:

a. simple interest; at the end of one year you will have earned $\$ 3$ of interest

b. annual compounding; at the end of one year you will have earned more than $\$ 3$ of interest because of the compounding

c. quarterly compounding; at the end of one year you will have earned more than $\$ 3$ of interest because of the compounding

d. actually, you will be indifferent among the three choices. In one year there will be no difference in the amount of interest earned. Only if you plan to leave the money in the account for more than one year will you have a preference for one account over another.

Before comparing the performance of students in the traditional engineering economics analysis course and the GBC course, an analysis was performed to determine if there were significant differences in the average student profile. The type of analysis used was the box-and-whisker plots to compare the SAT scores (verbal and quantitative) of students taking each course. As can be gleaned from Figure 3, there were no significant differences between the two student cohorts, with the mean SAT score lying just above $1200 .^{27}$

Box-and-whisker plots were also used to compare the performance of both cohorts of students, those in the

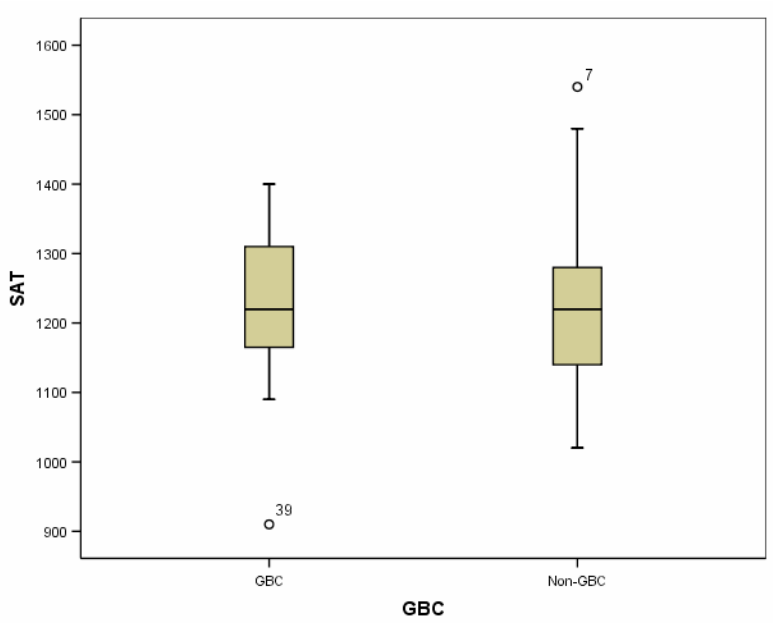

Figure 3: Box-and-whisker plot of SAT scores. 
traditional engineering economy course and those in the GBC course, on the pre- and post-tests. The same examination was administered on the first class day (pre-test) and at the end of the course (post-test). As shown in Figure 4, students taking the GBC course scored higher than the non-GBC students ( taking the traditional engineering economy course), though not at a significant level, and there was great overlap between the two populations. The non-GBC students scored significantly better on the post test than did the GBC students as shown in Figure 5. ${ }^{27}$ This was not a surprising finding for several reasons. First, roughly one third of the class time in the GBC course was devoted to formal engineering economy lectures, as the remainder of the course was dedicated to technical writing and technical speaking. In contrast, nearly $100 \%$ of the content in the traditional course is devoted to engineering economy. However, because of the integrated nature of the GBC course, one could argue that more than one third of the course contained engineering economy content. Because this was the first offering in this format, and by this professor, one could also contend that subsequent offerings under the same circumstances might yield higher student outcomes. Further, as the pilot offering consisted of a two-course sequence, GBC followed by a Technical Entrepreneurship course, a full comparison of student outcomes at the half-way point isn't fully justified. ${ }^{27}$

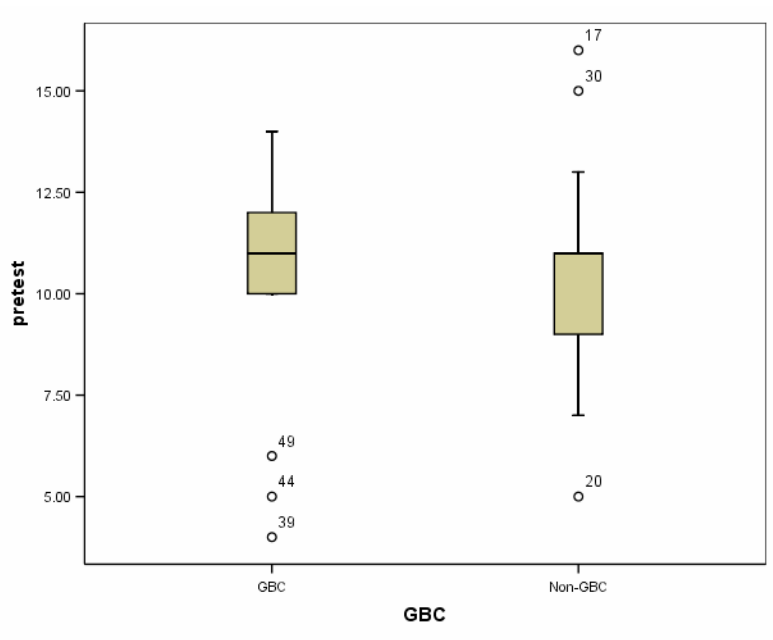

Figure 4: Box-and-whisker plot of pre-test scores.

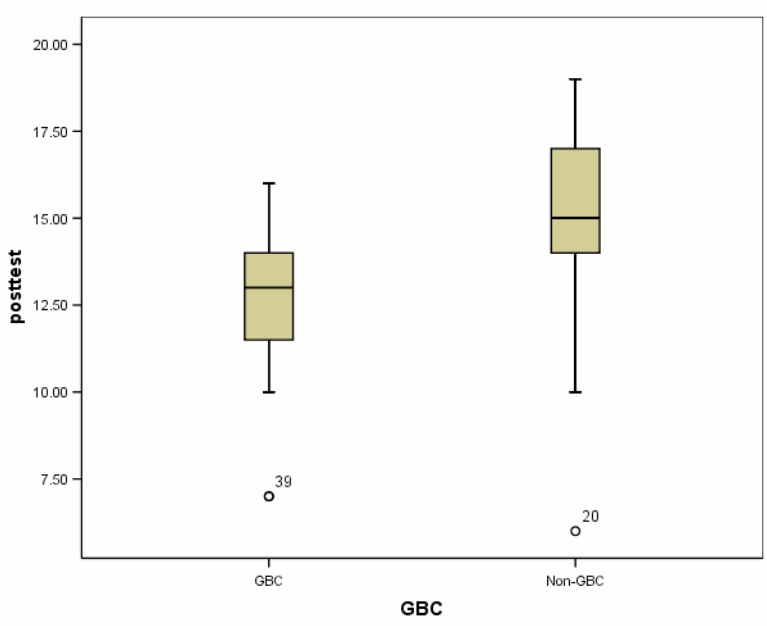

Figure 5: Box-and-whisker plot of post-test scores.

To better understand the differences in the performance of the two cohorts of students on engineering economy content taught in two different formats, a further analysis was conducted. The twenty problems on the exam were weighted from 1 to 5 by the engineering professor instructing the engineering economy portion of the GBC course as to relevance to the engineering economy component of the FE exam. Table II shows the distribution of these weightings. The average rating was 3.5 , implying that most of the questions were relevant to the FE exam.

\begin{tabular}{||l|l|l|l|l|c||}
\hline TABLE II: FE Relevance Scores of Pre/Post Exam \\
\hline Relevance rating (5 $\rightarrow 1$ scale; 5 most relevant) & 5 & 4 & 3 & 2 & 1 \\
\hline Number of exam questions with this score & 6 & 4 & 6 & 1 & 3 \\
\hline
\end{tabular}

A box-and-whisker analysis comparing student performance of the two cohorts on the pre/post exams considering the weight of each exam question was conducted. As shown in Figure 6, this 
analysis also shows that the students in the traditional engineering economy course scored significantly better than those in the GBC course. This was also the case when considering only those six questions weighted with the highest relevance (relevance rating of 5 ) as shown in Figure 7. Both of these analyses show a trend similar to that of exam as a whole, considered without weighting (Figure 5). ${ }^{27}$ Although this trend may be attributed to the greater amount of engineering economy exposure students received in the traditional course, it was suspected that the extent of that difference might be reduced when FE-relevance was considered.

In additional to purely academic performance, students were asked to provide feedback on other aspects of the course. The most common positive response dealt with appreciation for the enthusiasm of the associated faculty members and the perceived practical benefits of the technical speaking portion of the course. The most common negative comment eluded to the yet unrefined integration of course topics and content. These student observations are consistent with the experimental and pilot nature of the course. Overall, students' impressions were overwhelming positive.

The technical writing and technical speaking portions of the course were not designed during this first GBC offering to be so directly comparable to a

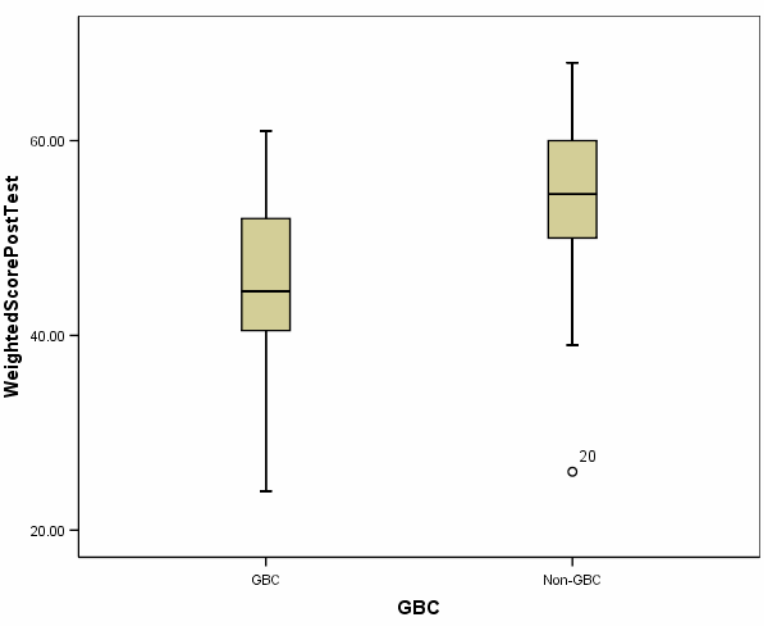

Figure 6: Box-and-whisker plot considering problem weight.

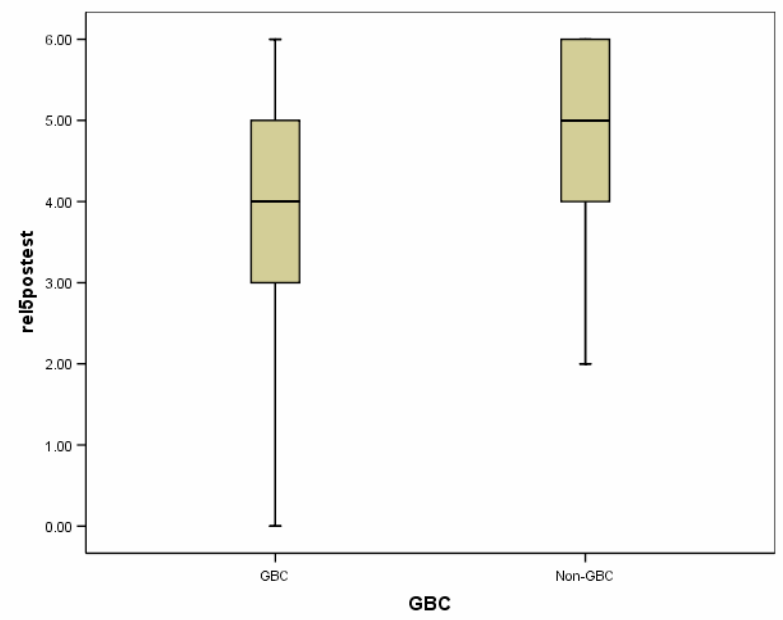

Figure 7: Box-and-whisker plot considering problems with weight of 5. companion course. It was not possible to compare the engineering economy knowledge of the GBC students after the second course in the sequence (Technical Entrepreneurship) because most of the students did not matriculate to that second course. Most of the students had already used up their course-substitution possibilities.

\section{Summary and Conclusions}

A comparison of student performance in a traditional engineering economy course and the pilot first course of a two-course sequence also integrating global issues, entrepreneurship, and technical writing, technical speaking, and engineering economy instruction was conducted. There were no differences in the average academic preparation of students from the two cohorts. Roughly one third of the instruction of the first course (GBC) was devoted to engineering economy. Students from both cohorts performed at a similar level on an engineering economy 
exam given at the beginning of the course. Students who took the traditional engineering economy course performed at a significantly higher level on the post test than the GBC students. This was true for raw scores and scores weighted for problem relevance to the FE exam. The trend of these results is consistent with students receiving less engineering economy instruction in the GBC course. The technical writing and technical speaking components of the course were not as stringently compared. Because most students did not matriculate through the two-course sequence, the engineering economy knowledge of the students could not be evaluated after the complete two-course sequence.

\section{Future Work}

During the fall 2007 term, a following-on section of GBC was offered. It was adjusted based on the experiences and feedback from the fall 2006 offering. ${ }^{28}$ Elements were also established to more directly compare the technical writing and technical speaking components. Further, most of the students are expected to matriculate to the follow-on course in the sequence, Technical Entrepreneurship, after which further evaluations of student learning outcomes will be conducted. While the intent and outcomes of these efforts appear positive, a significant concern remains as to their sustainability because of the high number of faculty and effort involved.

Bibliography

1. Ramalhoto, M.F., Akay, A. (2006) "Globalization and Engineering Education," European Journal of Engineering Education, June 2006, Vol 31, 247-248.

2. Newberry, B. (2005) “Engineering Globalization: Oxymoron or Opportunity?" IEEE Technology and Society Magazine, Fall 2005, 8-15.

3. Becker, F.S. (2006) "Globalization, Curricula Reform and the Consequences for Engineers Working in a International Company," European Journal of Engineering Education, June 2006, Vol 31, 261-272.

4. Nehdi, M., Rehan, R. (2007) "Raising the Bar for Civil Engineering Education: Systems Thinking Approach," Journal of Professional Issues in Engineering Education \& Practice, April 2007, Vol 133, 115-125.

5. Goldberg, J. (2005) “Senior Design: Teaching Entrepreneurship in Senior Design Courses," IEEE Engineering in Medicine and Biology Magazine, March/April 2005, 17.

6. Prusak, A. (2006) "Introduction to Global Engineering: Use of Standards and Cultural Differences," Proceedings of the $36^{\text {th }}$ ASEE/IEEE Frontiers in Education Conference, S3C-14-18.

7. Coyle, E.J., Jamison, L.H., Oakes, W.C. (2005) "EPICS: Engineering Projects in Community Service," International Journal of Engineering Education, February 2005, Vol 21, 139-150.

8. Brito, C.d.R., Ciampi, M.M., Dudny, D. (2006) "Work in Progress: "Cultural Immersion': A Collaborative work among Countries in Engineering Education," Proceedings of the $36^{\text {th }}$ ASEE/IEEE Frontiers in Education Conference, S2C-23-24.

9. Loftus, M. (2007) "Cream of the Crop," ASEE PRISM, Summer 2007.

10. Kelley, B.S., Boon, K.L., Fry, C.C., Abrahams, M.D. (2006) “Developing a Global

Technical/Business/Communication Experience for Students," Proceedings of the 2006 ASEE Gulf-Southwest Annual Conference, 7 pps.

11. Fry, C.C., Leman, G. (2007) "International Technology Entrepreneurship: Immersion into Interdisciplinary Innovation $\left(\mathrm{I}^{5}\right)$ in Shanghai," Proceedings of the $37^{\text {th }}$ ASEE/IEEE Frontiers in Education Conference, T1A-1-7. 12. Tsay, R.S. (2007) “An Entrepreneurship Emulation Platform," Proceedings of the IEEE International Conference on Microelectronic Systems Education, 0-7695-2849-X/07.

13. Bowie, D., Donaldson, A., Peter, D., Rand, J. (2002) "Business and Engineering Project Interaction," Proceedings of the $32^{\text {nd }}$ ASEE/IEEE Frontiers in Education Conference, F4F-12.

14. Simoneau, R.J., Magenau, J.M., Ford, R.M. (2005) "Work in Progress- On Building a Business/Engineering Education Partnership," Proceedings of the $35^{\text {th }}$ ASEE/IEEE Frontiers in Education Conference, F1D-16-17. 15. Lord, M. (2007) “2 for 1,” ASEE PRISM, October 2007. 
16. Bordoff, J.E., Deich, M., Kahane, R., Orszag, P.R. (2006) "Promoting Opportunity and Growth through Science, Technology, and Innovation," Strategy Paper Series (Hamilton Project), Brookings Institution Press, Washington, 1-15.

17. Coates, E.R., Vajpayee, S.K., Juneau, J. (2003) "Introducing Engineering Economy Students to Real Options," Proceedings of the 2003 ASEE Annual Conference and Exposition, 2003-1139.

18. Sarfaraz, A., Shraibati, T. (2006), "Increasing Student Engagement in Engineering Economy Class,"

Proceedings of the 2006 ASEE Annual Conference and Exposition, 2006-2182.

19. Bafna, K., Aller, B. (2007) "Enhancing the Learning of Engineering Economy with Innovative Technology and

Teaching," Proceedings of the 2007 ASEE Annual Conference and Exposition, Conference Proceedings, 2007-2641. 20. Russ, J., Van, D. (2007) "Using Student-led Current Events Discussions to Meet Specific ABET Outcomes through Engineering Economy," Proceedings of the 2007 ASEE Annual Conference and Exposition, 2007-2826. 21. Bursic, K. (2006) "Applying Engineering Economic Analysis to Contemporary Problems with Global and Societal Implications," Proceedings of the 2006 ASEE Annual Conference and Exposition, 2006-570. 22. Kelley, B.S., Bradley, W.L., Thomas, J.B. (2006) "Student-Aimed Appropriate Technology Engineering Projects in Kenya," Proceedings of the 2006 ASEE Gulf-Southwest Annual Conference, 10 pps.

23. Kelley, B.S., Marshall, L.A. (2007) "Successful Academic and Administrative Partnerships at Baylor," Proceedings of the 2007 ASEE Gulf-Southwest Annual Conference, 13 pps.

24. Fry, C.C, Leman, G., Doty, R., Sriram, R. (2007) "Technical International Technology Entrepreneurship in the Undergraduate Engineering and Computer Science Curriculum," Proceedings of the 2007 ASEE Gulf-Southwest Annual Conference, 10 pps.

25. Doty, R.T. (2007) "Analysis of First Part of the Experiment: GBC," Presentation presented to the ECS Board of Advocates, April 27, 2007. http://www.baylor.edu/content/services/document.php/44445.pdf.

26. Johnson, K.R., (2006) “ECO 3308 Pre/Post Text," Baylor University, Fall 2006, 20 questions, 5 pps.

27. Booth, W.A. (2007) "Global Business Communication: Evaluation Process," Presentation presented to the ECS Board of Advocates, April 27, 2007. http://www.baylor.edu/content/services/document.php/44445.pdf.

28. Bradley, W., Grinols, A., Blalock, G., Jordan, W., Leman, G., Fry, C. (2008) "Incorporating Global Entrepreneurship Courses into an Engineering Curriculum," Proceedings of the $12^{\text {th }}$ Annual NCIIA Annual Conference, 12 pps. 